\title{
Antibiotic resistance genes in different animal manures and their derived organic fertilizer
}

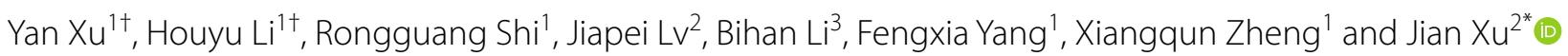

\begin{abstract}
Background: The prevalence of antibiotic resistance genes (ARGs) in animal manure poses a threat to environmental safety. Organic fertilizers fermented by livestock and poultry manure are directly applied to farmland and have the potential to cause outbreaks of bacterial resistance in agricultural environments. This study investigated the composition of ARGs in different animal manures and their derived organic fertilizers.

Results: The results showed that the abundance of several ARGs, such as sul2, TetB-01, TetG-01 and TetM-01, in organic fertilizer samples was 12-96\% lower than that in animal manure. However, the abundance of TetK and ermC was higher in animal manure than in organic fertilizers. No correlation between ARGs and environmental factors such as $\mathrm{pH}, \mathrm{TN}$, and antibiotics was observed by redundancy analysis (RDA). Procrustes analysis revealed a significant correlation between bacterial community structures and ARG abundance $(r=0.799, p<0.01)$. Nonmetric multidimensional scaling (NMDS) analysis suggested that microorganisms in organic fertilizer may be derived from animal manure. Additionally, the abundance of pathogenic bacteria (especially Actinomadura) would increase rather than decrease in manure compared to organic fertilizer.

Conclusion: The diversity and abundance of most ARGs significantly decreased from animal manure to organic fertilizer. Microorganisms in the prepared organic fertilizer may mainly be inherited from the animal manure. The results also showed that the pathogens in the prepared organic fertilizer would significantly reduce, but would still cause partial pathogen proliferation.
\end{abstract}

Keywords: Antibiotic resistance gene, Animal manure, Organic fertilizer, Pathogen

\section{Background}

Antibiotics are a class of medicines extensively used for promoting growth and controlling diseases on livestock and poultry farms [1]. However, up to $30-90 \%$ of the administered antibiotics are excreted through urine and manures, leading to the accumulation of residual

\footnotetext{
*Correspondence: xujian@craes.org.cn

${ }^{\dagger}$ Yan Xu and Houyu Li contributed equally to this work

${ }^{2}$ State Key Laboratory of Environmental Criteria and Risk Assessment,

State Environmental Protection Key Laboratory of Ecological Effect

and Risk Assessment of Chemicals, Chinese Research Academy

of Environmental Sciences, Beijing 100012, China

Full list of author information is available at the end of the article
}

antibiotics in the livestock environment [2-4]. Typical concentrations of antibiotics in livestock manure and poultry are generally in the range of $1-10 \mathrm{mg} / \mathrm{kg}$ and could be as high as $200 \mathrm{mg} / \mathrm{kg}$ [5]. According to previous studies, the content of enrofloxacin and ciprofloxacin in chicken manure were $61300 \mu \mathrm{g} / \mathrm{kg}$ and $18800 \mu \mathrm{g} /$ $\mathrm{kg}$, respectively [6]. High levels of residual antibiotics in manure provided selective pressure to the native microbial communities after the application of manure in soil [7-9], and bacteria could acquire antibiotic resistance genes (ARGs) via horizontal gene transfer or spontaneous mutation, thereby causing the proliferation of resistant bacteria $[10,11]$.
Springer Open

(c) The Author(s) 2020. This article is licensed under a Creative Commons Attribution 4.0 International License, which permits use, sharing, adaptation, distribution and reproduction in any medium or format, as long as you give appropriate credit to the original author(s) and the source, provide a link to the Creative Commons licence, and indicate if changes were made. The images or other third party material in this article are included in the article's Creative Commons licence, unless indicated otherwise in a credit line to the material. If material is not included in the article's Creative Commons licence and your intended use is not permitted by statutory regulation or exceeds the permitted use, you will need to obtain permission directly from the copyright holder. To view a copy of this licence, visit http://creativecommons.org/licenses/by/4.0/ 
ARGs could enter the environment via discharge of animal manure, leading to the contamination of soil, water and crops [12]. Most of the recent research focused on the quantitative detection of ARGs in manure and their surrounding environment [13]. For example, a total of 15 tetracycline resistance genes were detected in the soils around a pig farm [14]. The abundance of resistance genes was reported to be highly enriched in animal manures (121,000-fold in a farm in Beijing, 39,000-fold in a farm in Jiaxing and 57,000-fold in a farm in Pu Tian) [15]. Fang et al. study found that there were multidrug resistance (MDR) genes in stream water, which were disseminated from pig feedlot to surrounding stream via pig manure fertilization [16]; and Zhang et al. study described that cattle manure application increased the abundance of ARGs in plant root, while poultry manure application increased ARGs in rhizosphere, root endophyte and phyllosphere [17]. Thus, the continuous increase or high persistence of ARGs in livestock environments may pose potential threats to human health and the ecological environment $[18,19]$.

Composting is widely used to treat and re-utilize animal manures [20-22]. It has been reported that ARGs cannot be completely removed by fertilizer production during composting, which could even cause the proliferation of resistant bacteria [23, 24]. Although studies have shown a decrease in individual ARGs after composting, risks of ARG propagation still existed $[25,26]$. To the best of our knowledge, no systematic evaluation is available on the comparison of ARG composition both in livestock manure and their derived organic fertilizers. The relationship of ARGs in different animal manures and their derived organic fertilizers is insufficient as well. This study is devoted to addressing this concern, with the following objectives: (1) investigate the ARG composition in different animal manure and fermented organic fertilizers; (2) explore the effect of bacterial communities on ARG changes, and (3) demonstrate the variations of antibiotic-resistant pathogens in manure and organic fertilizers.

\section{Materials and methods}

\section{Sample collection and analysis}

Animal manures and organic fertilizers were obtained from different organic fertilizer enterprises in China. Three kinds of animal manure, including chicken manure (JF1, JF2, JF3, JF4, JF5), cow manure (NF1, NF2, NF3, NF4, NF5), and sheep manure (YF1, YF2, YF3), were collected from different organic fertilizer factories. The different numbers indicate different sources of animal manure. These fertilizers were prepared by aerobic composting of the raw materials. Five types of organic fertilizers were derived from a single manure $(\mathrm{JF} 1 \rightarrow \mathrm{JM} 1$,
$\mathrm{JF} 3 \rightarrow \mathrm{JM} 3, \quad J F 4 \rightarrow \mathrm{JM} 4), \quad(\mathrm{YF} 1 \rightarrow \mathrm{YM} 1, \quad \mathrm{NF} 2 \rightarrow \mathrm{NM} 2)$. The following organic compound fertilizers were derived from a mixture of various animal manures $(\mathrm{NF} 4+\mathrm{YF} 1+\mathrm{JF} 5 \rightarrow \mathrm{NYJM} 1, \quad \mathrm{NF} 1+\mathrm{YF} 2 \rightarrow \mathrm{NYM} 1$, $\mathrm{YF} 2+\mathrm{JF} 3 \rightarrow \mathrm{YJM} 1, \mathrm{YF} 3+\mathrm{JF} 2 \rightarrow \mathrm{YJM} 2$ ). Three samples were collected from manure/fertilizer at each site and combined to prepare one sample. The mixed sample was divided into two portions: one subsample was used for analysing physicochemical properties, and the second subsample was freeze-dried and stored at $-80{ }^{\circ} \mathrm{C}$ for DNA extraction and microbial community structure analysis. Antibiotic concentrations were determined according to the approach by Li et al. [27].

\section{DNA extraction}

DNA extraction was carried out from $0.2 \mathrm{~g}$ animal manure and prepared organic fertilizer samples using a Power Soil DNA isolation kit (Omega Bio-Tek, Norcross, GA, USA) according to the kit manual. The extracted DNA was quantified with a Nano Drop spectrophotometer (Thermo Scientific) and stored at $-80{ }^{\circ} \mathrm{C}$ until PCR analysis.

\section{HT-qPCR}

ARGs were quantitatively analysed with the Smart Chip Real-Time PCR System (WaferGen Biosystems Inc., Fremont, CA, USA) equipped with a high-throughput quantitative reaction platform (Qiyin Biological Technology Co., Ltd., Shanghai, China). A total of 51 primers targeting resistance genes and a pair of bacterial universal 16S rRNA gene primers were selected according to the literature [28]; five sulfonamide resistance genes (SRGs), 16 tetracycline resistance genes (TRGs), two fluoroquinolone resistance genes (FRGs), five aminoglycoside resistance genes, $11 \beta$-lactamase resistance genes, seven macrolide-lincosamide-streptomycin B (MLSB) resistance genes, two vancomycin resistance genes, three other/efflux resistance genes, and the $16 \mathrm{~S}$ rRNA gene were targeted. The experimental conditions and the data processing procedure were the same as those published in the literature [29].

\section{S high-throughput sequencing}

The 16S V4 region was analysed by the Illumina HiSeq 2500 platform to study the bacterial community composition. The chimaeras were filtered using USE$\mathrm{ARCH}$, and the remaining sequences were clustered into 97\% similarity operational classification units (OTUs). Each OTU sequence was selected by default, and the ribosomal database item classifier with the latest version of the green gene database with a confidence threshold of $80 \%$ was used to classify OTUs. 


\section{Data analysis}

Weighted and unweighted UniFrac tests were performed using Mothur to determine the statistical significance of structural similarities among communities across different sampling locations. Ordination plotting with nonmetric multidimensional scaling (NMDS) was employed to visualize the beta-diversity information. Principal component analysis (PCA, based on Bray-Curtis distance) was used with STAMP software. R3.1.2 with Vegan 2.0 was used for the Mantel test and Procrustes analysis to determine the correlation between ARG data and bacterial communities. Additional, Network analysis showed the relationship between the host bacteria and ARGs using R 3.5.3 and Gephi 0.9.2. Redundancy analysis (RDA) was conducted using CANOCO 4.5 (Microcomputer Power, USA) to establish the underlying correlations between the ARGs and environmental factors.

\section{Results and discussion}

\section{Diversity and abundance of ARGs in animal manures} and organic fertilizer

The abundance and diversity of 51 target ARGs in animal manures and their prepared organic fertilizer were obtained through HT-qPCR. The results showed that the ARG diversity in the organic fertilizer samples was relatively lower than that in the animal manure samples $(p<0.05)$ (Fig. 1a). The absolute abundance of ARGs in the animal manure and organic fertilizer samples was in the range of $2.1 \times 10^{5}$ to $7.8 \times 10^{5}$ copies/g and $1.6 \times 10^{5}$ to $7.3 \times 10^{5}$ copies/g, respectively, which was similar to the findings by Zhang et al. [30]. A previous study also found that composting could reduce the abundance and diversity of ARGs in animal manure, likely due to the inactivation of some microorganisms by high temperature [31].

The types of ARGs in the animal manure from different breeds were significantly different due to the differences in manure properties and microbial composition (Fig. 1b) [32]. The detection rates of ARG subtypes from a single kind of animal manure to manufactured organic fertilizer samples (JF1 $\rightarrow$ JM1 and NF2 $\rightarrow$ NM2) were reduced by $42 \%$ and $34.6 \%$, respectively. However, the detection rates of ARG subtypes from multiple animal manures (mixing of NF and YF, YF and JF) to compound organic fertilizer samples increased by $28 \%$ (NF1 + YF2 $\rightarrow$ NYM1) and $24 \%$ $(\mathrm{YF} 2+\mathrm{JF} 3 \rightarrow \mathrm{YJM} 1)$, respectively (Fig. 1a). These results indicated that the composting process could reduce the release of partial ARG subtypes from single manure to organic fertilizer, which were consistent with the study of previous observations [33]. It is noteworthy that the composite organic fertilizer fermented by multiple manures would increase the diversity of ARGs, highlighting the importance of manure management concerning the fate of ARGs [34] (Additional file 1: Table S1).

The chicken manure had the highest absolute abundance of ARGs $\left(2.8 \times 10^{5}-7.8 \times 10^{5}\right.$ copies/g), which was $2-4$ times higher than those in cow manure $\left(2.1 \times 10^{5}-\right.$ $3.3 \times 10^{5}$ copies/g) and sheep manure $\left(2.2 \times 10^{5}-\right.$ $5.1 \times 10^{5}$ copies/g) (Fig. 1c). Previous studies have shown that the difference in ARG levels between poultry manure and cattle manure may be related to the difference in antibiotic use patterns and microorganisms in manure among different species of livestock $[35,36]$. The removal efficiencies of ARGs in different animal manures and/or different treatment processes were also reported [15, 37]. Most TRGs (tetB-01, tetG-01 and tetM-01) decreased by $12-96 \%$ after composting (Fig. 1c), which was confirmed by previous findings [38, 39]. The abundance of tet $\mathrm{X}$ was higher than those of other ARGs in all samples, likely due to the broad range of potential hosts of tetX [34]. Some TRGs decreased, while others persisted or significantly increased (including tet $\mathrm{K}$ and tet $\mathrm{X}$ ) after thermophilic composting [40]. Compared with the raw response of animal manure, the abundance of individual ARGs (tetK) increased 2-216 times in the organic fertilizer. Ezzariai et al. reported that the abundance of tet $\mathrm{X}$ in swine manure decreased exponentially under anaerobic conditions [37]. The reason for this opposite trend is still being explored, since the resistance mechanism of tet $\mathrm{X}$ is still unknown $[15,41]$.

SRGs were predominant in all samples in terms of absolute abundance. From JF1 to JM1, the levels of the sul1 and sul2 genes decreased from $1.1 \times 10^{5}$ copies/g to $10^{0}$ copies/g and from $1.2 \times 10^{5}$ copies/g to $1.58 \times 10^{1}$ copies/g, respectively. Similar results were found in the study of Wolters et al. [33], that the level of sul 2 dramatically decreased during composting. The abundance of MLSB resistance genes (ermA, erm $\mathrm{B}$, ermF and ermX) significantly decreased by $10-98 \%$ from manure to organic fertilizer (Fig. 1c), lower than the abundances of TRGs and SRGs. The abundance of MLSB resistance genes was related to the low use of macrolides during feeding. The response of ARGs varied in composting due to ecological complex microbial processes. This result suggested that the composting process may cause individual ARGs proliferation.

Fresh manure composting is a feasible approach to decrease the level of certain ARGs before their application to farmland. However, most ARGs remain or even proliferate after composting, which may be caused by differences in external conditions, such as raw materials, environmental factors or microbial communities [42]. A recent study also showed that variations in microbial communities may have an impact on ARGs in composting [31]. 

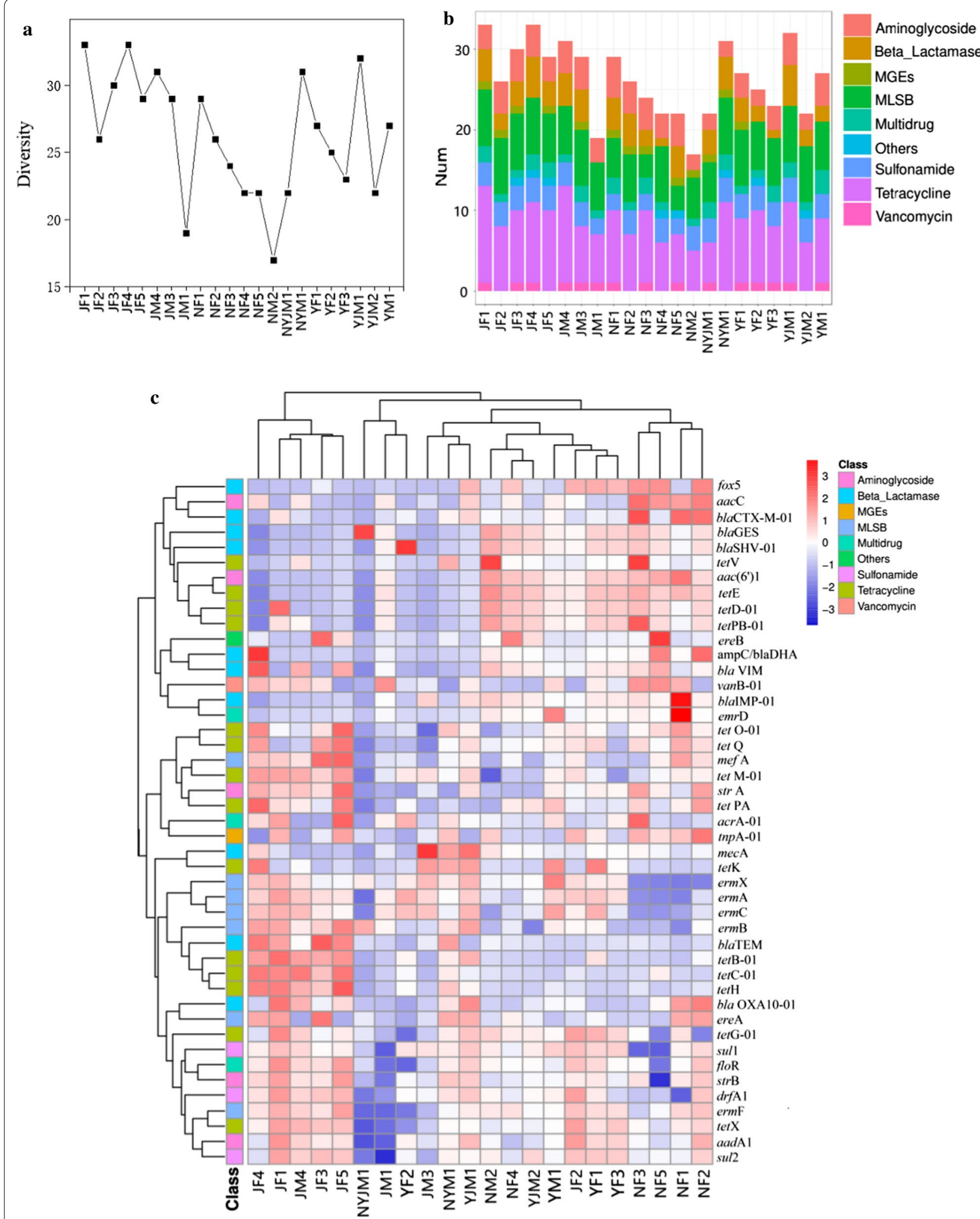

Fig. 1 a The diversity of ARGs in different animal manure and organic fertilizers. $\mathbf{b}$ The diversity of ARG subtypes in different animal manure and organic fertilizers. c Heatmap of the relative abundance of ARGs in animal manure and organic fertilizer 


\section{Microbial communities in animal manure and organic fertilizer}

As shown in Fig. 2, no significant correlation between the ARGs and the environmental factors was observed in this study. Previous studies have found that ARGs were subjected to relatively smaller impacts from the environmental factors than microbial community [31].

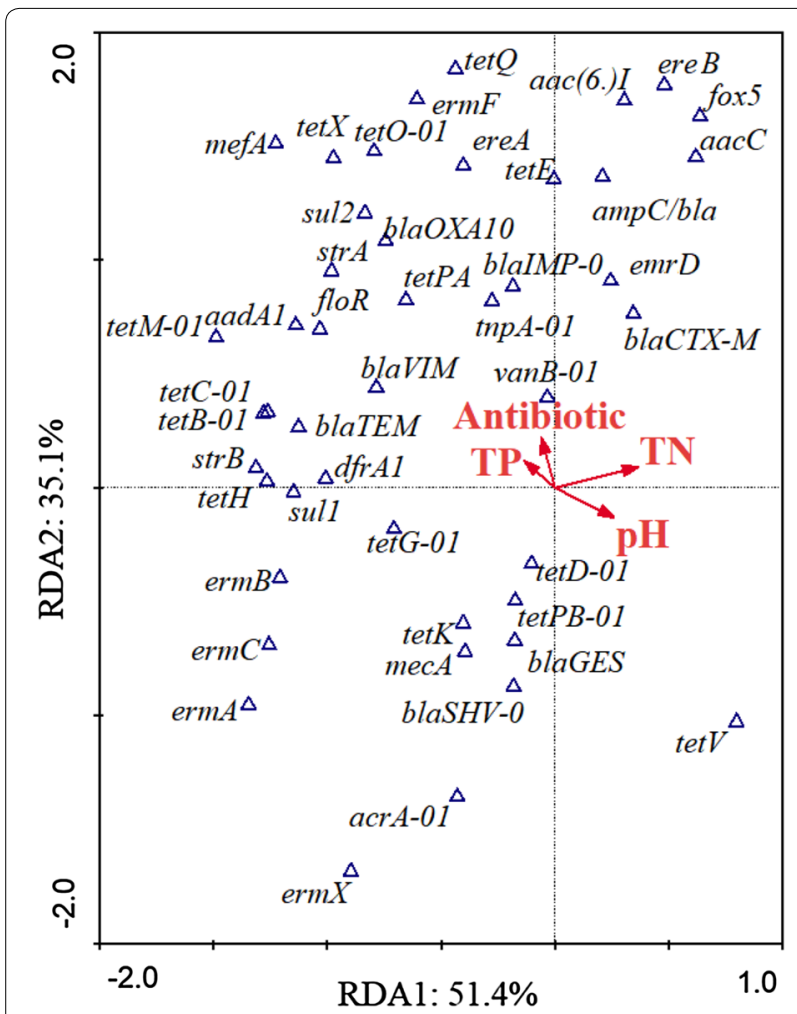

Fig. 2 Redundancy analysis (RDA) for correlation analysis between ARGs and environmental factors
And we focused on the microbial community structures in animal manure and organic fertilizer samples. The results are shown in Fig. 3a, b. The composition and abundance of microbial communities varied greatly in different sample classifications. The compound organic fertilizer NYJM had the highest microbial diversity (Fig. 3a), and the samples of different animal manures and organic fertilizer were clustered into different categories (Fig. 3b). From the sorted map of the microbial community in Fig. 3b, the manure samples partially overlapped with the aggregated organic fertilizer samples (such as NF and NM), suggesting that the bacterial community structures in organic fertilizer were similar to those in manure from the corresponding composting source.

Compared with their derived fertilizer, the abundance of microorganisms decreased in cow manure; conversely, an increase in microbial abundance was observed in chicken manure, which might be related to composting conditions and manure nutritional structure (Fig. 3a) [43, 44]. In particular, the abundance of microorganisms among JM samples varied dramatically, which might originate from the condition of livestock farms as well as individual differences in animals (including age and species) [45]. As shown in Fig. 3b, the composition of the microbial community between animal manure and their derived organic fertilizer (e.g., $\mathrm{YF} \rightarrow \mathrm{YM}$ and $\mathrm{JF} \rightarrow \mathrm{JM}$ ) was significantly different. Interestingly, the Bray-Curtis distance between $\mathrm{YF}$ and YM and between JF and JM was closer than that between the YF or JF samples and other organic fertilizer samples. The overlap between NF and NM indicated that the microbial community structures of NF and NM were more similar than those of the other samples. The intersections between the YJM, JM, JF, and YF
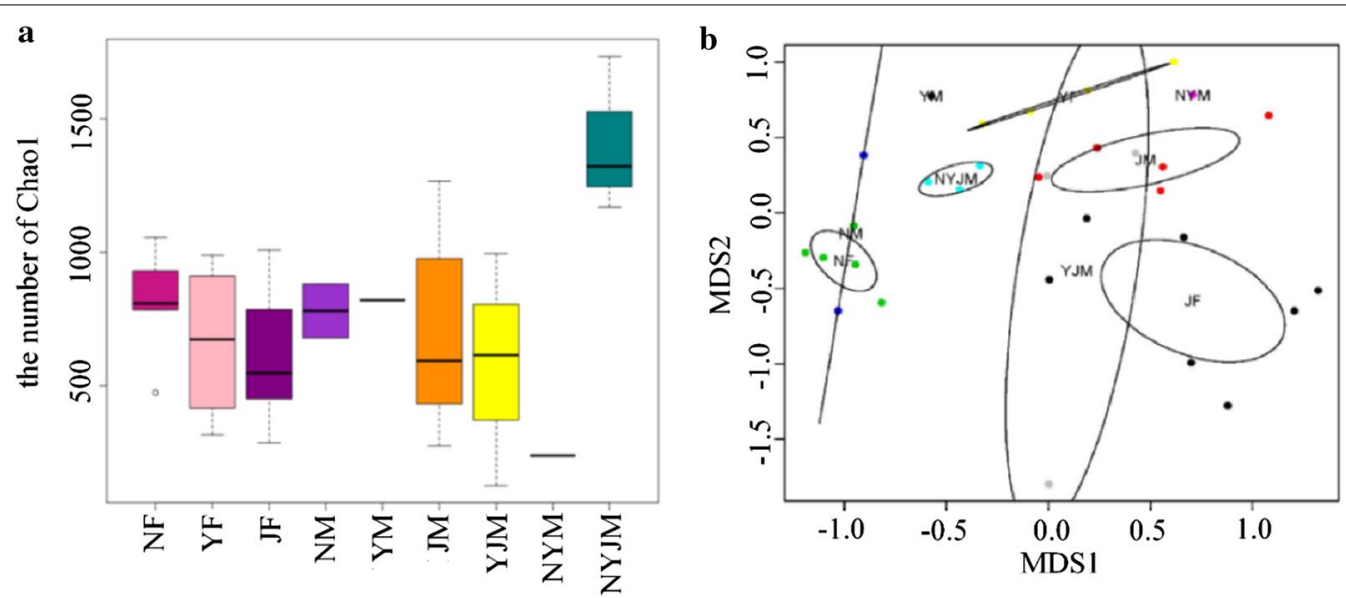

Fig. 3 a Alpha diversity of Chao 1 for each group sample; $\mathbf{b}$ nonmetric multidimensional scaling (NMDS) plot of all samples 
samples suggested that there was a correlation between the microbial composition of animal manure and their derived organic fertilizer.

\section{Relationship between the bacterial communities and ARGs}

The results from the Mantel test indicated that ARG abundance was substantially correlated with bacterial community structures based on Bray-Curtis distance. Procrustes analysis showed that clustering based on the abundance of ARGs and 16S OTUs exhibited a goodnessof-fit (based on Bray-Curtis distance, sum of squares $M^{2}=0.476, r=0.799, p<0.01,999$ permutations), indicating that the bacterial community structures exerted a significant influence on ARG abundance. This finding was consistent with a previous study showing that the change in the microbial community structure was the major factor driving the variation of ARG profiles in animal manure and organic fertilizer $[46,47]$. The PCA results also confirmed that ARGs within different animal manures and organic fertilizers showed a similar distribution pattern of the bacterial communities (Fig. 4). It was concluded that the variation in ARGs from animal manure to organic fertilizer was strongly correlated with the microbial community. The shift of the bacterial communities played a key role in the direct change of the ARG patterns [34]. It was noted that the presence of pathogens in the microbial community would not only decrease the productivity of livestock and poultry breeding, but also increase the risk of ARGs spreading from organic fertilizer to the agricultural environment.

\section{The fate of pathogens from animal manure to organic} fertilizer

The variability in the relative abundance of the top 20 genera was determined to evaluate the risk of pathogens from manure to organic fertilizer (Fig. 5). It is worth noting that most of them were pathogens in the top 20 most abundant genera. Corynebacterium-1, Virgibacillus, Streptomyces and Actinomadura were the major genera in the animal manure and organic fertilizer samples. After composting, the relative abundance of pathogens was altered, but the dominant genus was still Corynebacterium-1; compost usually has a heterogeneous population composed of human and animal pathogens that could cause disease in livestock [48]. The relative abundance of Virgibacillus was significantly reduced in animal manure compared to prepared organic fertilizer (especially in JF-JM). In addition, the abundance of Actinomadura in organic fertilizer was 2-300 times higher than that in animal manure. These two genera were carriers of antibiotic resistance genes (such as erm $\mathrm{X}$ and tetPA), and their abundances were found to have a similar reduction trend as ARGs after composting. The genera Actinomadura and Virgibacillus belong to the phylum Actinobacteria and are opportunistic pathogens that cause disease in animals and plants [49]. Lv et al. identified that Actinobacteria were prominent in the thermophilic stage, and the groups in the study could probably carry and disseminate ARGs [50]. The abundance of Pseudomonas (phylum Proteobacteria), which was found to be an opportunistic pathogen carrying most ARGs with multiple resistance, was significantly increased from animal manure

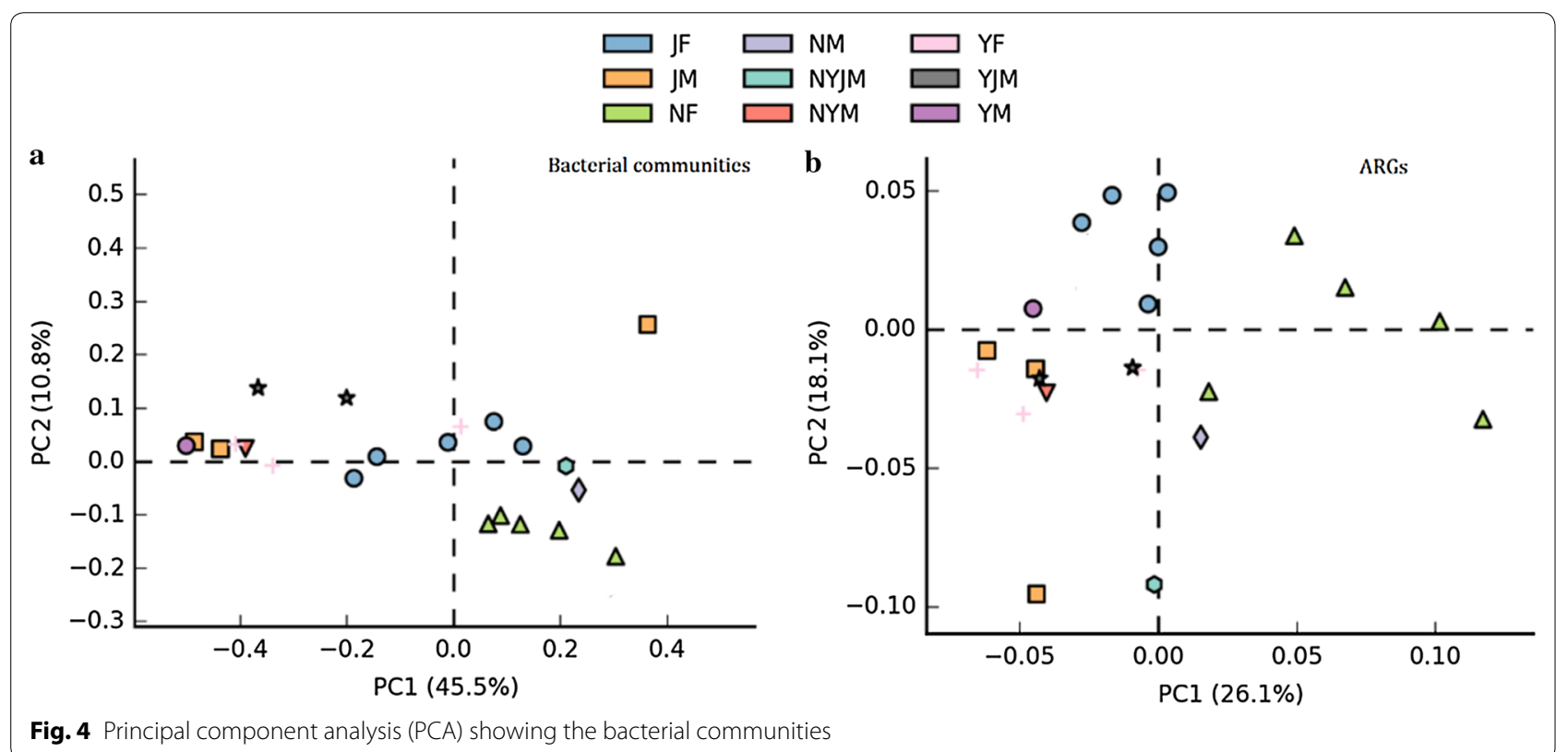



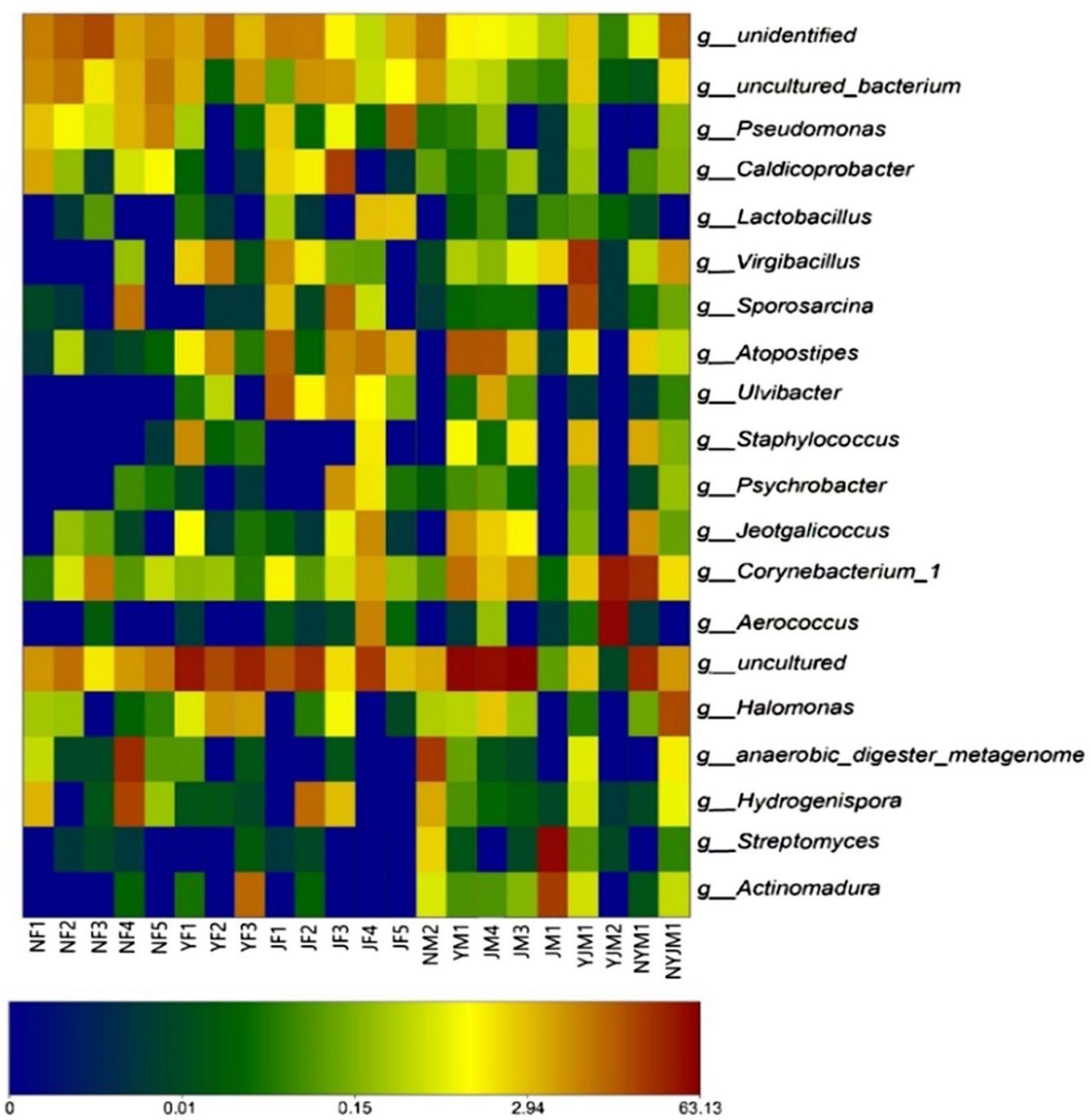

Relative abundance of commmuntiy

Fig. 5 Heatmap of the relative abundance of the top 20 genera in animal manure and organic fertilizer

to organic fertilizer $[30,51]$. Network analysis was conducted to determine the correlation between ARGs and the top bacterial genera, which may allow the potential host bacteria for ARGs to be determined. As illustrated in Fig. 6, there were significant correlations between ARGs and the potential host bacteria in the animal manure and their derived organic fertilizer samples $(p<0.05$ and $R>0.60$ ). In addition to the host bacteria obtained above, the genus Atopostipes belonging to the phylum Firmicutes were found to contain potential host bacteria for erm $\mathrm{A}, \operatorname{erm} \mathrm{B}, \operatorname{erm} \mathrm{X}$, tet $\mathrm{K}$, and tet $\mathrm{M}-01$.

Pathogens could not be completely removed after composting animal manure to organic fertilizer, causing partial proliferation. Significant correlations between pathogens and ARGs were observed, suggesting that the pathogens might become important hosts of ARGs [49]. Therefore, once antibiotic-resistant pathogens are ubiquitous in organic fertilizer, they are bound to pose a threat to the health of farmland soil and crops.

\section{Conclusions}

This study investigated the composition of ARGs and bacterial community structure between different animal manures and their derived organic fertilizers. The diversity and abundance of most ARGs significantly decreased from animal manure to organic fertilizer. Microorganisms in the prepared organic fertilizer may mainly be inherited from animal manure. The results 


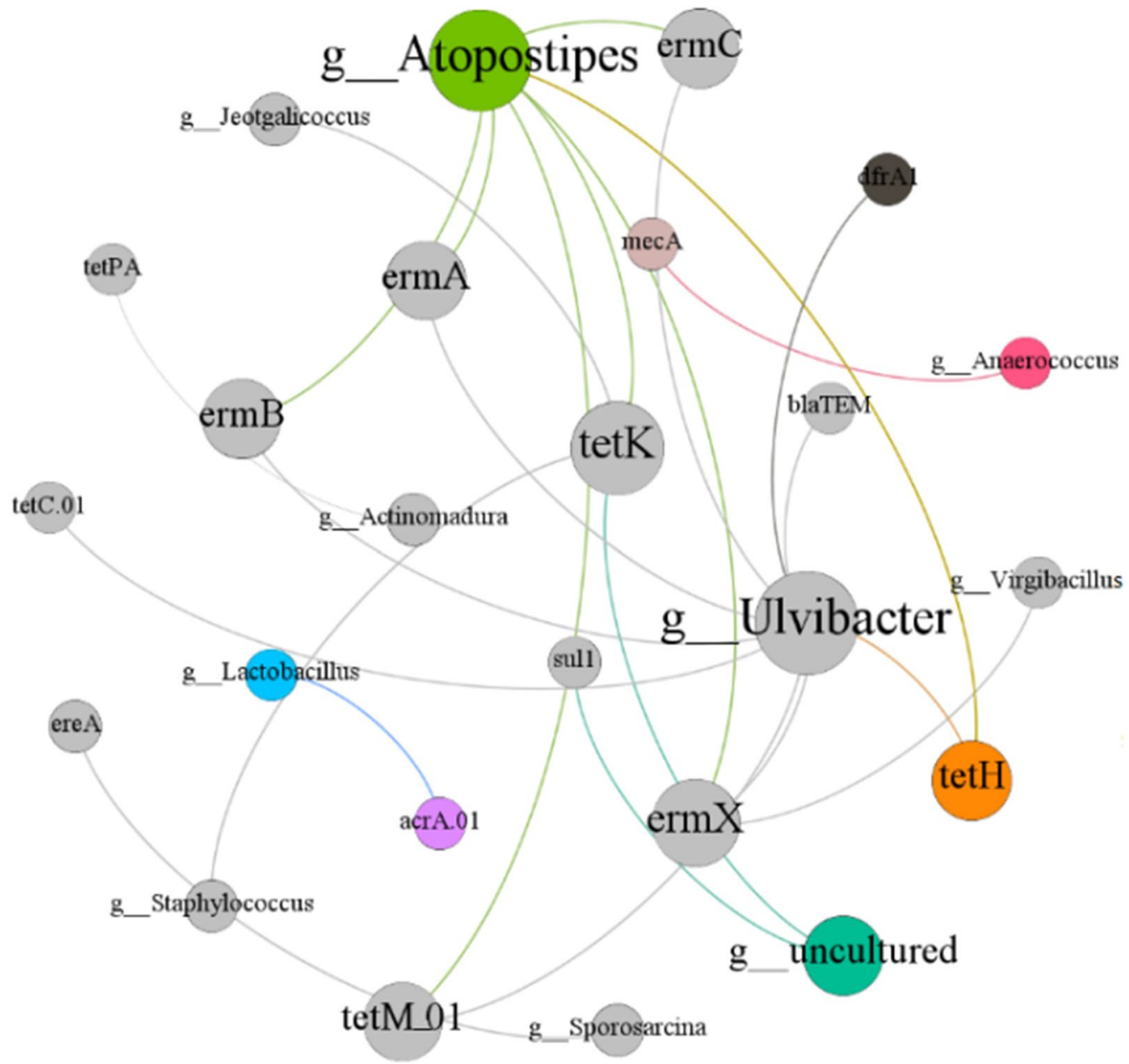

Fig. 6 Network analysis of ARGs and potential host bacteria (top 20 genera) $(p<0.05, R>0.60)$

also showed that the pathogens in the prepared organic fertilizer would significantly reduce, but would still cause partial pathogen proliferation. It is urgent and necessary to explore optimal fermentation processes to improve the removal efficiency of ARGs and pathogens in animal manure.

\section{Supplementary information}

Supplementary information accompanies this paper at https://doi. org/10.1186/s12302-020-00381-y.

Additional file 1: Table S1. The 52 genes primers.

\section{Abbreviations}

ARGs: Antibiotic resistance genes; NMDS: Nonmetric multidimensional scaling; SRGs: Sulfonamide resistance genes; TRGs: Tetracycline resistance genes; FRGs: Fluoroquinolone resistance genes; MLSB: Macrolide-lincosamide-streptomycin B; OTUs: Operational classification units; PCA: Principal component analysis; RDA: Redundancy analysis.

\section{Acknowledgements}

Not applicable.

\section{Authors' contributions}

$Y X, H L$ and RS were involved in the experiments and manuscript writing, and $J L, B L, F Y$ and $X Z$ were responsible for the data analysis. JX contributed to the study design and manuscript correction. All authors read and approved the final manuscript.

\section{Funding}

This work was funded by the National Key R\&D Program of China (2018YFC 1901004), National Natural Science Foundation of China (41807369) and China Postdoctoral Science Foundation (2018M640209).

\section{Availability of data and materials}

The data sets used and analysed during the current study are available from the corresponding author upon reasonable request.

\section{Ethics approval and consent to participate}

Not applicable.

\section{Consent for publication}

Not applicable. 


\section{Competing interests}

The authors declare that they have no competing interests.

\section{Author details}

${ }^{1}$ Agro-Environmental Protection Institute, Ministry of Agriculture and Rural Affairs, Tianjin 300191, China. ${ }^{2}$ State Key Laboratory of Environmental Criteria and Risk Assessment, State Environmental Protection Key Laboratory of Ecological Effect and Risk Assessment of Chemicals, Chinese Research Academy of Environmental Sciences, Beijing 100012, China. ${ }^{3}$ College of Life Sciences, Shandong Agricultural University, Tai'an 271018, China.

Received: 17 May 2020 Accepted: 15 July 2020

Published online: 22 July 2020

\section{References}

1. Done HY, Venkatesan AK, Halden RU (2016) Does the recent growth of aquaculture create antibiotic resistance threats different from those associated with land animal production in agriculture? AAPS J 17:513-524

2. Chiesa L, Nobile M, Arioli F, Britti D, Trutic N, Pavlovic R, Panseri S (2015) Determination of veterinary antibiotics in bovine urine by liquid chromatography-tandem mass spectrometry. Food Chem 185:7-15

3. Guo T, Lou CL, Zhai WW, Tang XJ, Hashmi MZ, Murtaza R, Li Y, Liu XM, Xu JM (2018) Increased occurrence of heavy metals, antibiotics and resistance genes in surface soil after long-term application of manure. Sci Total Environ 635:995-1003

4. Heuer H, Schmitt H, Smalla K (2011) Antibiotic resistance gene spread due to manure application on agricultural fields. Curr Opin Microbiol 14:236-243

5. Liu YW, Feng Y, Cheng DM, Xue JM, Wakelin S, Li ZJ (2018) Dynamics of bacterial composition and the fate of antibiotic resistance genes and mobile genetic elements during the co-composting with gentamicin fermentation residue and lovastatin fermentation residue. Bioresour Technol 261:249-256

6. Janusch F, Scherz G, Mohring SAI, Hamscher G (2014) Determination of fluoroquinolones in chicken feces-A new liquid-liquid extraction method combined with LC-MS/MS. Environ Toxicol Phar 38:792-799

7. Cleary DW, Bishop AH, Zhang LH, Topp E, Wellington EMH, Gaze WH (2016) Long-term antibiotic exposure in soil is associated with changes in microbial community structure and prevalence of class 1 integrons. FEMS Microbiol Ecol 92:fiw159

8. Jechalke S, Heuer H, Siemens J, Amelung W, Smalla K (2014) Fate and effects of veterinary antibiotics in soil. Trends Microbiol 22:536-545

9. Nordenholt RM, Goyne KW, Kremer RJ, Lin CH, Lerch RN, Veum KS (2016) Veterinary antibiotic effects on atrazine degradation and soil microorganisms. J Environ Qual 45:565-575

10. Peng S, Wang YM, Zhou BB, Lin XG (2015) Long-term application of fresh and composted manure increase tetracycline resistance in the arable soil of eastern China. Sci Total Environ 506-507:279-286

11. Cheng DM, Feng YY, Liu YW, Xue JM, Li JZ (2019) Dynamics of oxytetracycline, sulfamerazine, and ciprofloxacin and related antibiotic resistance genes during swine manure composting. J Environ Manage 274:102-109

12. He LY, Ying GG, Liu YS, Su HC, Chen J, Liu SS, Zhao JL (2016) Discharge of swine wastes risks water quality and food safety: antibiotics and antibiotic resistance genes from swine sources to the receiving environments. Environ Int 92-93:210-219

13. Sui QW, Meng XS, Wang R, Zhang JY, Yu DW, Chen MX, Wang YW, Wei YS (2018) Effects of endogenous inhibitors on the evolution of antibiotic resistance genes during high solid anaerobic digestion of swine manure. Bioresource Technol 270:328-336

14. Wu N, Qiao M, Zhang B, Cheng WD, Zhu YG (2010) Abundance and diversity of tetracycline resistance genes in soils adjacent to representative swine feedlots in china. Environ Technol 44:6933-6939

15. Zhu YG, Johnson TA, Su JQ, Qiao M, Guo GX, Stedtfeld RD, Hashsham SA, Tiedje JM (2013) Diverse and abundant antibiotic resistance genes in Chinese swine farms. Proc Natl Acad Sci USA 110:3435-3440

16. Fang $H$, Han L, Zhang H, Long Z, Cai L, Yu Y (2018) Dissemination of antibiotic resistance genes and human pathogenic bacteria from a pig feedlot to the surrounding stream and agricultural soils. J Hazard Mater 357:53-62

17. Zhang YJ, Hu HW, Chen QL, Singh BK, Yan H, Chen DL, He JZ (2019) Transfer of antibiotic resistance from manure-amended soils to vegetable microbiomes. Environ Int 130:104912

18. Negreanu Y, Pasternak Z, Jurkevitch E, Cytryn E (2012) Impact of treated wastewater irrigation on antibiotic resistance in agricultural soils. Environ Sci Technol 46:4800-4808

19. Wang BY, Guo XH, Wang C, Ma JY, Niu FF, Zhang HF, Yang B, Liang WW, Han F, Jiang YQ (2015) Identification and characterization of plant-specific NAC gene family in canola (Brassica napus L.) reveal novel members involved in cell death. Plant Mol Biol 87:395-411

20. Wang J, Ben WW, Zhang Y, Yang M, Qiang ZM (2015) Effects of thermophilic composting on oxytetracycline, sulfamethazine, and their corresponding resistance genes in swine manure. Environ Sci Proc Impacts 17:1654-1660

21. Wu XF, Wei YS, Zheng JX, Zhao X, Zhong WK (2011) The behavior of tetracyclines and their degradation products during swine manure composting. Bioresour Technol 102:5924-5931

22. Zhao JC, Sun $X N$, Awasthi MK, Wang Q, Ren XN, Li RH, Chen HY, Wang MJ, Liu T, Zhang ZQ (2018) Performance evaluation of gaseous emissions and Zn speciation during Zn-rich antibiotic manufacturing wastes and pig manure composting. Bioresour Technol 267:688-695

23. Ray P, Chen CQ, Knowlton KF, Pruden A, Xia K (2017) Fate and effect of antibiotics in beef and dairy manure during static and turned composting. J Environ Qual 46:45-54

24. Chen ZQ, Wang Y, Qin X (2018) Effects of chlortetracycline on the fate of multi-antibiotic resistance genes and the microbial community during swine manure composting. Environ Pollut 237:977-987

25. Wallace JS, Garner E, Pruden A, Aga DS (2018) Occurrence and transformation of veterinary antibiotics and antibiotic resistance genes in dairy manure treated by advanced anaerobic digestion and conventional treatment methods. Environ Pollut 236:764-772

26. Selvam A, Xu DL, Zhao ZY, Wong JWC (2012) Fate of tetracycline, sulfonamide and fluoroquinolone resistance genes and the changes in bacterial diversity during composting of swine manure. Bioresour Technol 126:383-390

27. Li LX, Guo CS, Fan SS, Lv JP, Zhang Y, Xu Y, Xu J (2018) Dynamic transport of antibiotics and antibiotic resistance genes under different treatment processes in a typical pharmaceutical wastewater treatment plant. Environ Sci Pollut 25:30191-30198

28. Luo Y, Mao DO Rysz M, Zhou DX, Zhang HJ, Xu L, Alvarez PJJ (2010) Trends in antibiotic resistance genes occurrence in the Haihe River, China. Environ Sci Technol 44:7220-7225

29. Su JQ, Wei B, Ou-Yang WY, Huang FY, Zhao Y, Xu HJ, Zhu YG (2015) Antibiotic resistome and its association with bacterial communities during sewage sludge composting. Environ Sci Technol 49:7356-7363

30. Zhang RR, Gu J, Wang XJ, Li Y, Zhang KY, Yin YN, Zhang X (2018) Contributions of the microbial community and environmental variables to antibiotic resistance genes during co-composting with swine manure and cotton stalks. J Hazard Mater 358:82-91

31. Sun W, Gu J, Wang XJ, Qian X, Peng HL (2019) Solid-state anaerobic digestion facilitates the removal of antibiotic resistance genes and mobile genetic elements from cattle manure. Bioresour Technol 274:287-295

32. Ji XL, Shen QH, Liu F, Ma J, Xu G, Wang YL, Wu MH (2012) Antibiotic resistance gene abundances associated with antibiotics and heavy metals in animal manures and agricultural soils adjacent to feedlots in Shanghai, China. J Hazard Mater 235-236:178-185

33. Wolters B, Ding GC, Kreuzig R, Smalla K (2016) Full-scale mesophilic biogas plants using manure as C-source: bacterial community shifts along the process cause changes in the abundance of resistance genes and mobile genetic elements. FEMS Microbiol Ecol 92:fiv163

34. Ezzariai A, Hafidi M, Khadra A, Aemig Q, El Felsa L, Barret M, Merlina G, Patureau D, Pinelli E (2018) Human and veterinary antibiotics during composting of sludge or manure: global perspectives on persistence, degradation, and resistance genes. J Hazard Mater 359:465-481

35. Cheng GY, Hao HH, Xie SY, Wang X, Dai MH, Huang LL, Yuan ZH (2014) Antibiotic alternatives: the substitution of antibiotics in animal husbandry? Front Microbiol 5:217

36. Han XM, Hu HW, Chen QL, Yang LY, Li HL, Zhu YG, Li XZ, Ma YB (2018) Antibiotic resistance genes and associated bacterial communities in 
agricultural soils amended with different sources of animal manures. Soil Biol Biochem 126:91-102

37. Ling Z, Dong YH, Wang H (2010) Residues of veterinary antibiotics in manures from feedlot livestock in eight provinces of China. Sci Total Environ 408:1069-1075

38. Yu ZT, Michel FC, Hansen G, Wittum T, Morrison M (2005) Development and application of real-time PCR assays for quantification of genes encoding tetracycline resistance. Appl Environ Microbiol 71:6926-6933

39. Storteboom HN, Kim SC, Doesken KC, Carlson KH, Davis JG, Pruden A (2007) Response of antibiotics and resistance genes to high-intensity and low-intensity manure management. J Environ Qual 36:1695-1703

40. Hang W, Li HY, Gilbert JA, Li HB, Wu LH, Liu M, Wang LL, Zhou QS, Yuan JX, Zhang ZZ (2015) Housefly larva vermicomposting efficiently attenuates antibiotic resistance genes in swine manure, with concomitant bacterial population changes. Appl Environ Microbiol 81:7668-7679

41. Wang FH, Qiao M, Su JQ, Chen Z, Zhou X, Zhu YG (2014) High throughput profiling of antibiotic resistance genes in urban park soils with reclaimed water irrigation. Environ Sci Technol 48:9079-9085

42. Tien YC, Li B, Zhang T, Scott A, Murray R, Sabourin L, Marti R, Topp E (2017) Impact of dairy manure pre-application treatment on manure composition, soil dynamics of antibiotic resistance genes, and abundance of antibiotic-resistance genes on vegetables at harvest. Sci Total Environ 581:32-39

43. Chen QL, An XL, Li H, Su JQ, Ma YB, Zhu YG (2016) Long-term field application of sewage sludge increases the abundance of antibiotic resistance genes in soil. Environ Int 92-93:1-10

44. Zhao X, Wang JH, Zhu LS, Ge WL, Wang J (2017) Environmental analysis of typical antibiotic-resistant bacteria and ARGs in farmland soil chronically fertilized with chicken manure. Sci Total Environ 593-594:10-17

45. Huang P, Zhang Y, Xiao KP, Jiang F, Wang HC, Tang DZ, Liu D, Liu B, Liu YS, He $X$ (2018) The chicken gut metagenome and the modulatory effects of plant-derived benzylisoquinoline alkaloids. Microbiome 6:211
46. Zhang YJ, Li HC, Gu J, Qian X, Yin YN, Li Y, Zhang RR, Wang XJ (2016) Effects of adding different surfactants on antibiotic resistance genes and intl1 during chicken manure composting. Bioresour Technol 219:545-551

47. Sun W, Qian X, Gu J, Wang XJ, Zhang L, Guo AY (2017) Mechanisms and effects of arsanilic acid on antibiotic resistance genes and microbial communities during pig manure digestion. Bioresour Technol 234:217-223

48. Mohammadi NS, Mafakheri S, Abdali N, Barcena-Uribarri I, Tauch A, Benz R (2013) Identification and characterization of the channel-forming protein in the cell wall of Corynebacterium amycolatum. BBA-Biomembranes 1828:2574-2582

49. Lu LH, Zeng G, Fan CZ, Zhang JC, Chen AW, Chen M, Jiang M, Yuan YJ, Wu HP, Lai MY, He YB (2014) Diversity of Two-domain laccase-like multicopper oxidase genes in Streptomyces spp.: identification of genes potentially involved in extracellular activities and lignocellulose degradation during composting of agricultural waste. Appl Environ Microbiol 80:3305-3314

50. Lv BY, Xing MY, Yang J, Zhang LB (2015) Pyrosequencing reveals bacterial community differences in composting and vermicomposting on the stabilization of mixed sewage sludge and cattle dung. Appl Microbiol Biot 99:10703-10712

51. Wang $H X$, Wang $N$, Wang $B$, Zhao $Q$, Fang $H$, Fu CW, Tang $C X$, Jiang F, Zhou Y, Chen Y, Jiang QW (2016) Antibiotics in drinking water in shanghai and their contribution to antibiotic exposure of school children. Environ Sci Technol 50:2692-2699

\section{Publisher's Note}

Springer Nature remains neutral with regard to jurisdictional claims in published maps and institutional affiliations.

\section{Submit your manuscript to a SpringerOpen ${ }^{\circ}$ journal and benefit from:}

- Convenient online submission

- Rigorous peer review

- Open access: articles freely available online

- High visibility within the field

- Retaining the copyright to your article

Submit your next manuscript at $\boldsymbol{\nabla}$ springeropen.com 